Article

\title{
Influence of Climate Warming on Grapevine (Vitis vinifera L.) Phenology in Conditions of Central Europe (Slovakia)
}

\author{
Slavko Bernáth ${ }^{1}$, Oleg Paulen ${ }^{1 *}$, Bernard Šiška² ${ }^{2}$ Zuzana Kusá ${ }^{1}$ and František Tóth ${ }^{3}$
}

\author{
${ }^{1}$ Department of Fruit Production, Viticulture and Enology, Faculty of Horticulture and Landscape Engineering, \\ Slovak University of Agriculture, Tulipánová 7, 94976 Nitra, Slovakia, slavko.bernath@uniag.sk, \\ zuzana.kusa@gmail.com, \\ 2 Štúrova 42, 94901 Nitra, Slovakia, bbeetless@gmail.com \\ ${ }^{3}$ Gemerprodukt Valice - OVD, Okružná 3771, 97901 Rimavská Sobota, Slovakia, ftoth@gemerprodukt..sk \\ *Correspondence: oleg.paulen@uniag.sk; 00421376415799
}

\begin{abstract}
Impact of warming on phenology of grapevine (Vitis vinifera L.) in conditions of Central Europe was evaluated at the locality of Dolné Plachtince in Slovakian wine region. In Welschriesling and Pinot Blanc model varieties there was observed onset of phenophases as defined in BBCH scale over 1985-2018 period. Based on the data obtained there was evaluated influence of average and average maximum temperature and GDD on onset of phenophases. The results observed indicate earlier budburst by 5-7 days, earlier beginning of flowering by 7-10 days, and earlier berry softening by 18 day, and harvest dates advanced by 8-10 days in average. In both varieties there was found the highest influence of the average monthly temperature in March on budburst, the highest influence of the average monthly temperature and the average maximum temperature in May on beginning of flowering, and the highest, statistically significant influence of the average maximum temperature in June on grape veraison. Warming observed in moderate climate conditions of northern wine regions in Central Europe (Slovakia) has not caused yet the changes in the grapevine phenology stable enough to require serious adaptation measures.
\end{abstract}

Keywords: climate change; grapevine; phenophase,

\section{Introduction}

In many regions of the world various phenomena have been observed which are attributed to climate change. Warming of an environment is among the basic phenomena related to climate change. Observed changes in 27 premium wine regions across the globe have shown an average growing season temperature from 1950 to 2000 by $1.3^{\circ} \mathrm{C}$ [1], while in Europe the increase was $1.7^{\circ} \mathrm{C}$ from 1950 to 2004 [2,3,4]. However, the rate of warming which has been observed over the recent decades varies among wine regions in Europe. In Adriatic coast of Central Italy average annual temperature increased by more than 0.5 ${ }^{\circ} \mathrm{C}$ from 70 -ties of $\mathrm{XX}$ century [5] though warming rate has weakened during last decade. In Palatine region of South-western Germany, the increase was $2.1^{\circ} \mathrm{C}$ from 70-ties [6], in Hérault department on the Mediterranean France it was $1.3^{\circ} \mathrm{C}$ within $1980-2006$ period [7]. In 1991-2014 period, average annual temperature increased by $0.9-1.1^{\circ} \mathrm{C}$ compared to its average value in the 1960-1990 period on the Slovakia's territory [8]. 
The impact of climate change is manifested not only in tendentious changes but also in the extreme events (warm winters, spring frosts etc.) with increasing frequency and seriousness [9]. This justifies the attention paid by viticultural sector to climate change. Grape production is higly sensitive to climate change and the key channels of its influence on grape and wine are through temperature, water, weather extremes and possibly $\mathrm{CO}_{2}$ itself [10]. Possible strong stimulative effect of rising atmospheric $\mathrm{CO}_{2}$ is reported [11].

According to HadCM3 climate model average predicted temperatures for the high quality wine producing regions will increase by $2.04{ }^{\circ} \mathrm{C}$ within 2000-2049 period [3]. Projected changing climate will have significant effect on the European viticultural geography. It will have detrimental impacts in southern Europe mainly due to increased dryness and cumulative thermal effects while regions in western and central Europe will benefit with higher wine quality and emerging new potential areas for viticulture [12, 13, 14]. The impact of changing climate is particular to each region because of the spatial variability over big areas. Regions may need to consider a shift in the mix of cultivars to produce best wine in future climates. Also legislative barriers may need to be overcome for new cultivars to be introduced into some regions [15].

Climate change influences agriculture/viticulture and calls forth adaptation and mitigation actions for farming communities to be more resilient. Viticulture is among the most challenged sectors. Understanding the changing suitability of regions for viticulture under climate change will help to develop adaptation strategies in traditional winegrowing regions [16]. In order to maintain profitability and to ensure long-term future producers will be required to adapt to changing climatic characteristics. Planning for adaptation is complicated due uncertainty about future conditions, management strategies are more often influenced by more pressing immediate concerns [17].

Climate change is exerting an increasingly profound influence on vine phenology and grape composition, and ultimately affects vinifications, wine microbiology and chemistry, and sensory aspects. [18]. The phenology of grapevine and berry ripening indices are extremely sensitive to climate and highly genotype-specific. Climate characterization and monitoring of grapevine phenology and berry biochemistry are efficient tools to define environmental vulnerability of wine regions and create basis for addressing strategies for future planning of viticulture practices [19]. Understanding of the interaction between weather conditions and berry/wine compounds will help with developing improved winemaking techniques as a part of adapting to future impacts of climate change [20]. Temperature is an essential factor influencing duration of phenophases. Meteorological conditions, including air temperature are changing from year to year which cause variations in onset and length of phenophases as well as grape quality [21]. In various studies a diversity in phenological response of grapevine cultivars was recorded with potential utilisation in adaptation to climate change. Later ripening cultivars advanced faster than earlier ripening ones. [22]. In Palatinate wine region (Germany) actual terms of bud break, flowering and veraison of Pinot cvs. and Riesling are 11-15, 18-22 and 16-22 days earlier respectively harvest dates are 25-40 days earlier actually compared to 70-ties of XX century. [6]. In Hungary a significant positive change 
occured in the value of the blooming average temperature, growing season average temperature, harvest maximum temperature, and growing season maximum temperature over the past 30 years [23]. Variability of phenological response has been observed not only between distant regions but also over short distances in a wine region which are related to local characteristics [24]. There are different phenological responses between vicinal regions with different altitudes. In Georgia for example, from 1994 advance of Rkatsiteli cv veraison was 5.9 days for 250-500 m a.s.l. while 18.1 days for 750-1000 m a.s.1. [25].

Changes in temperature, solar radiation, water availability and other climatic variables are improving sugar, phenolic compounds and vitamins in grapes. However, when these factors (temperatures, solar radiation, humidity) extend beyond certain tresholds crop quality will be reduced [26]. Among the most important climate change related effects are advanced harvest time and temperatures, increased grape sugar concentrations that lead to high wine alcohol levels, lower acidities and modification of varietal aroma compounds [18]. In cooler wine regions sugar accumulation is positively influenced by warmer conditions during veraison while malic acid content decreases [20].

In established winegrowing regions, over long history, growers have optimized yield and quality by choosing plant material and viticultural techniques according to climatic conditions, but as the climate changes adaptation measures that include changing of plant material (cultivars, rootstocks) [27, 28] and viticultural techniques e.g. changing trunk area, leaf area to yield ratio, pruning time are inevitable to maintain optimal period of harvest dates [29].

Climate plays a vital role in the terroir of given wine region asi it controls the factors which determine wine attributes and typicity. Changes in viticultural suitability over last decades, for viticulture in general and for specific cultivars have been reported for many wine regions. These will reshape geographical distribution of wine regions, and wine typicity may also be threatened in many cases [30]. Proper exploitation of the territory and local microclimate is among basic conditions of successful wine production. Thus determining connections between the territory and microclimate can lead to more accurate assessments of the vineyard and wine identities. [31]. It was find that cultivar diversity is able to lower projected loses of current winegrowing areas which suggests potential of in situ shifting cultivars to adapt viticulture to climate change [32]. Warmer climate conditions might be beneficial for maintaining the current grape cultivars with their current grape quality or cultivating new grape cultivars in new projected winegrowing areas [33]. Results of the study performed in Romania revealed a 2.4 million ha expansion of the area with the climate suitable for wine production within the country, a $180 \mathrm{~m}$ increase in altitude with the suitable climate up to a current maximum of $835 \mathrm{~m}$ asl; and northward shift of $0.036^{\circ}$ of area with the suitable climate [34]. In Hungary a significant change of Growing Degree Days (GDD) has been observed over the past 30 years - by $1240{ }^{\circ} \mathrm{C}$, and area planted with the cultivars that need more warmth has been extended [23]. Growing of grape has been spreading to new areas during recent decades. Warming of climate has been accelerated in the last few decades and made possible 
growing of hybride vine varietes and even some Vitis vinifera cultivars even in South Finland (Helsinki region) [35].

\section{Results}

\subsection{Temperature data}

The mean annual temperature ranged from $8.7{ }^{\circ} \mathrm{C}$ in 1996 to $11.55{ }^{\circ} \mathrm{C}$ in 2014 (Figure 1). Over the last 10 years assessed (2009-2018), it was on average $10.5{ }^{\circ} \mathrm{C}$, representing an increase of 1.4 by C compared to the long-term normal of 1960-1990 period. Trend analysis of the mean annual temperature over the assessed period shows statistically significant increase $(\mathrm{r}=0.6, \mathrm{p}=0.0002)$.

The average temperature of the growing season (IV.-IX.) over the evaluated 19852018 period was from $15.6^{\circ} \mathrm{C}$ in 1991 to $18.5^{\circ} \mathrm{C}$ in 2018 (Figure 1). Over the last 10 years assessed, it reached $17.5{ }^{\circ} \mathrm{C}$, representing an increase of $1,5^{\circ}$ compared to the long-term normal of 1960-1990 period. Trend analysis shows statistically significant increase of the mean growing season temperature $(r=0.57, \mathrm{p}=0.0004)$.

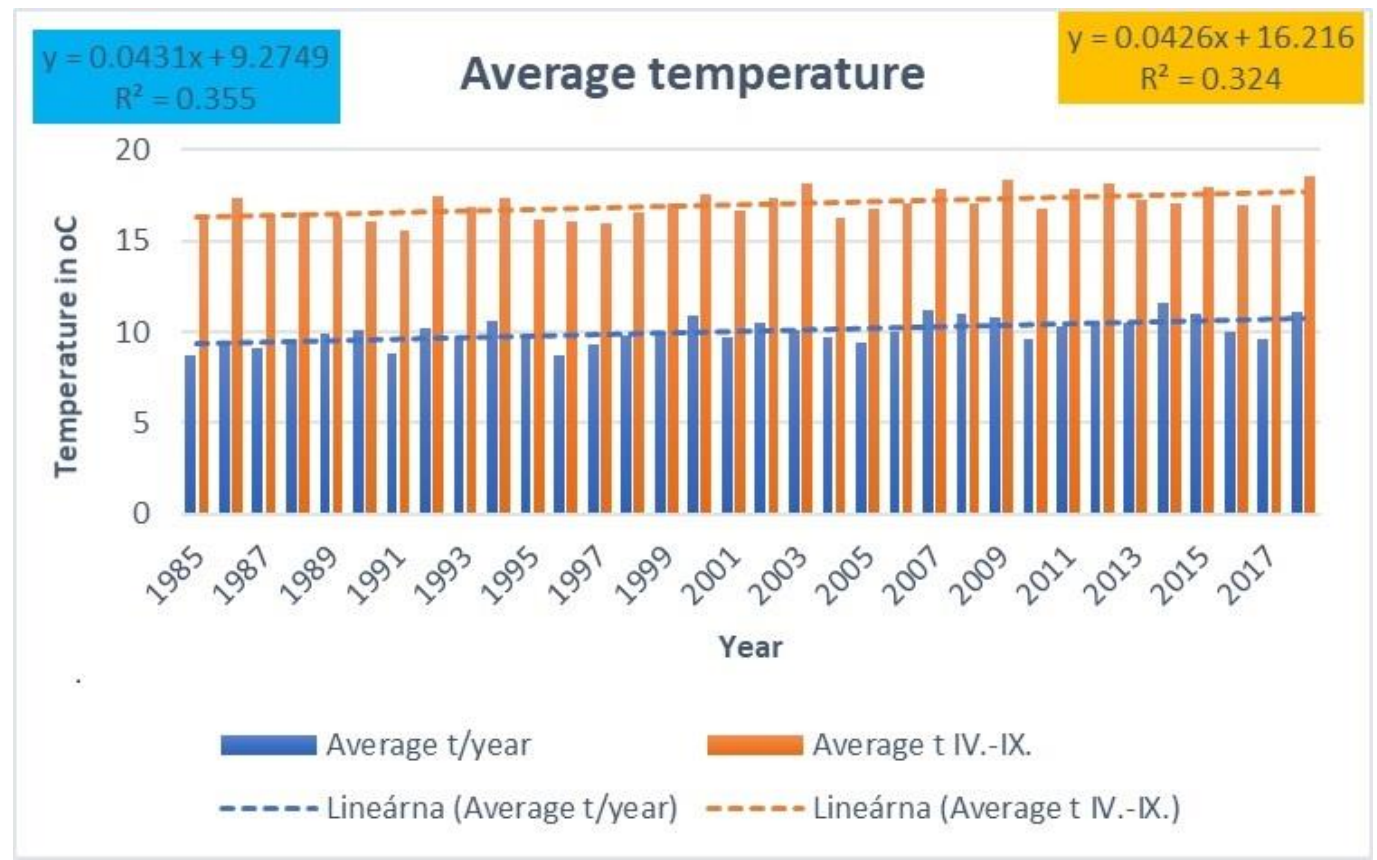

Figure 1. Average temperatures of year and growing season (April-September) over 1985-2018 period in the experimental site.

When assessing changes of the average monthly temperatures we compared the average temperatures over the last 10 years (2009-2018) with the long-term normal of 1960-1990 (Figure 2). The highest increases in average monthly temperature were recorded in April $2.1{ }^{\circ} \mathrm{C}$, in February and November $2.0^{\circ} \mathrm{C}$, in August $1.7{ }^{\circ} \mathrm{C}$, and in the months of June and July $1.4^{\circ} \mathrm{C}$. Statistically significant $(\mathrm{p}<0.05)$ increase of the average temperature was in June $(r=0.64, p=0.0001)$ and April $(r=0.34, p=0.0495)$. In the remaining months, the increase is not statistically significant. 


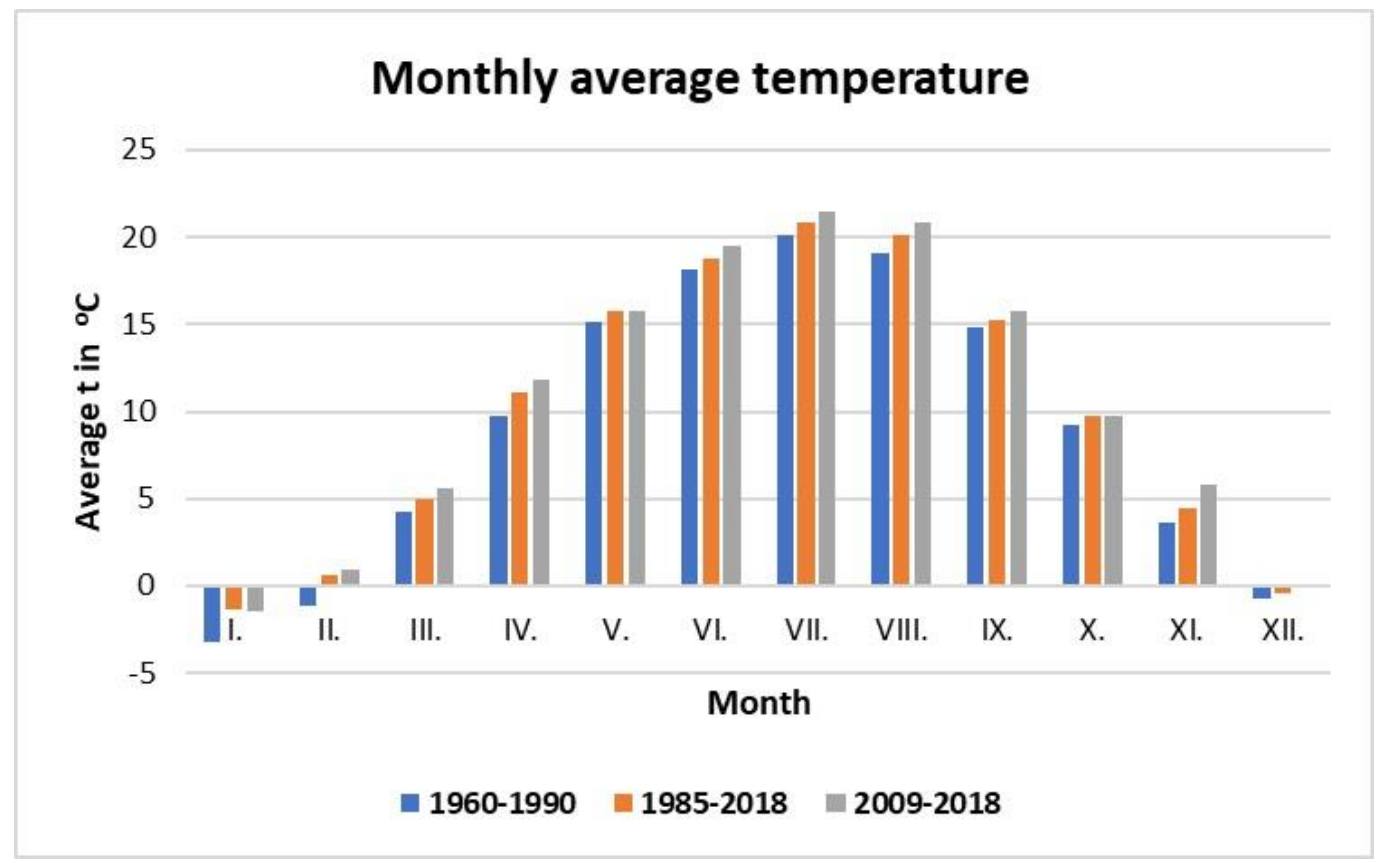

Figure 2. Monthly average temperatures in different periods - 1960-1990 (normal, reference period), $1985-2018$ (observed period), 2009-2018 (last decade of the observed period).

Of the bioclimatic indicators, the sum of effective temperatures - growth degree days (GDD) was assessed. The highest GDD was recorded in 20181646.7 degree days, the lowest in 1991 1155.9. The average GDD for the period of 1985-2018 was 1360 degree days. The tendency of GDD increase is statistically significant with a correlation coefficient $r=$ 0.55 and $p$ value 0.0008 .

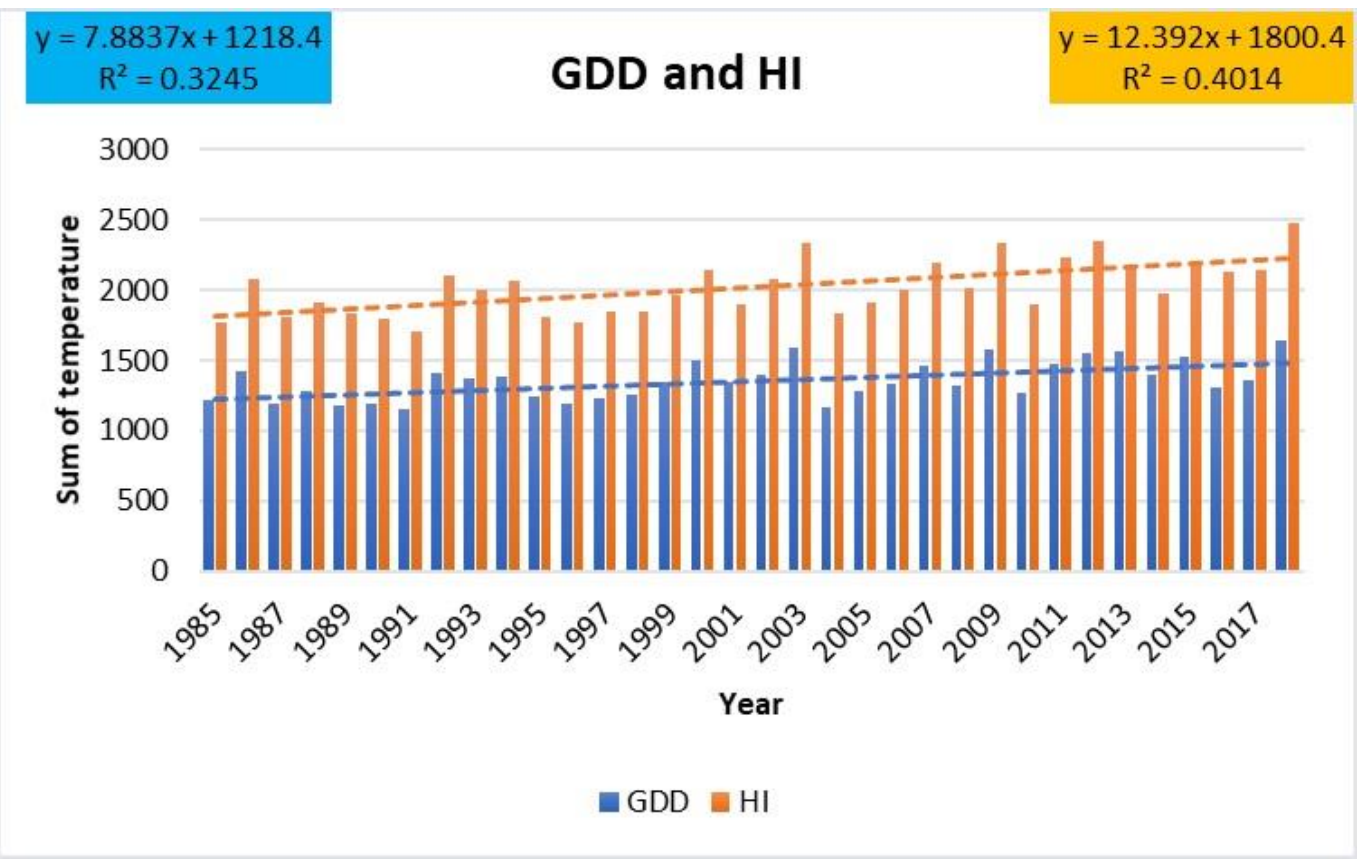

Figure 3. GDD and HI values in the years of the observed period.

The second bioclimatic indicator assessed was the Huglin index (HI). Over the observed period $1985-2018$ its avarage was $2017{ }^{\circ} \mathrm{C}$. The highest HI value was $2477.5^{\circ} \mathrm{C}$, 
in 2018 , the lowest $1705{ }^{\circ} \mathrm{C}$ in 1991 . The tendency of $\mathrm{HI}$ increase is statistically significant with a correlation coefficient $r=0.63$ and $\mathrm{p}$ value 0.0001 (Figure 3).

\subsection{Onset of phenophases}

Budburst (BBCH 08) - in Welschriesling the average onset in the assessed 1985-2018 period was April 20 (110 JD). The aerliest date of budburst was April 4, 2014, the latest May 3, 1987. Average date of Pinot Blanc beginning of budburst was April 15 (105 JD). The earliest date of budburst beginning was March 31, 2017 and the latest April 28, 1997. The trend of earlier budburst beginning in Welschriesling is statistically significant $(\mathrm{p}=$ 0.0007) with correlation coefficient value $r=-0.55$. In Pinot Blanc the trend of earlier budburst beginning is not statistically significant $(p=0.07, r=-0.3)$. When comparing the recent ten years (2009-2018) with first ten years assessed (1985-1994) budburst in Welschriesling and Pinot Blanc begins by 7 and 5 days earlier, respectively (Figure 4).

The average temperature in March has the biggest impact on budburst beginning in both varieties. Effect of the higher average temperature in March on earlier budburst beginning is statistically significant $(p=0.0000)$ and correlation coefficient value $r=-0.74$ (Welschriesling) and $\mathrm{r}=-0.73$ (Pinot Blanc) which indicates moderately strong relationship between the variables.

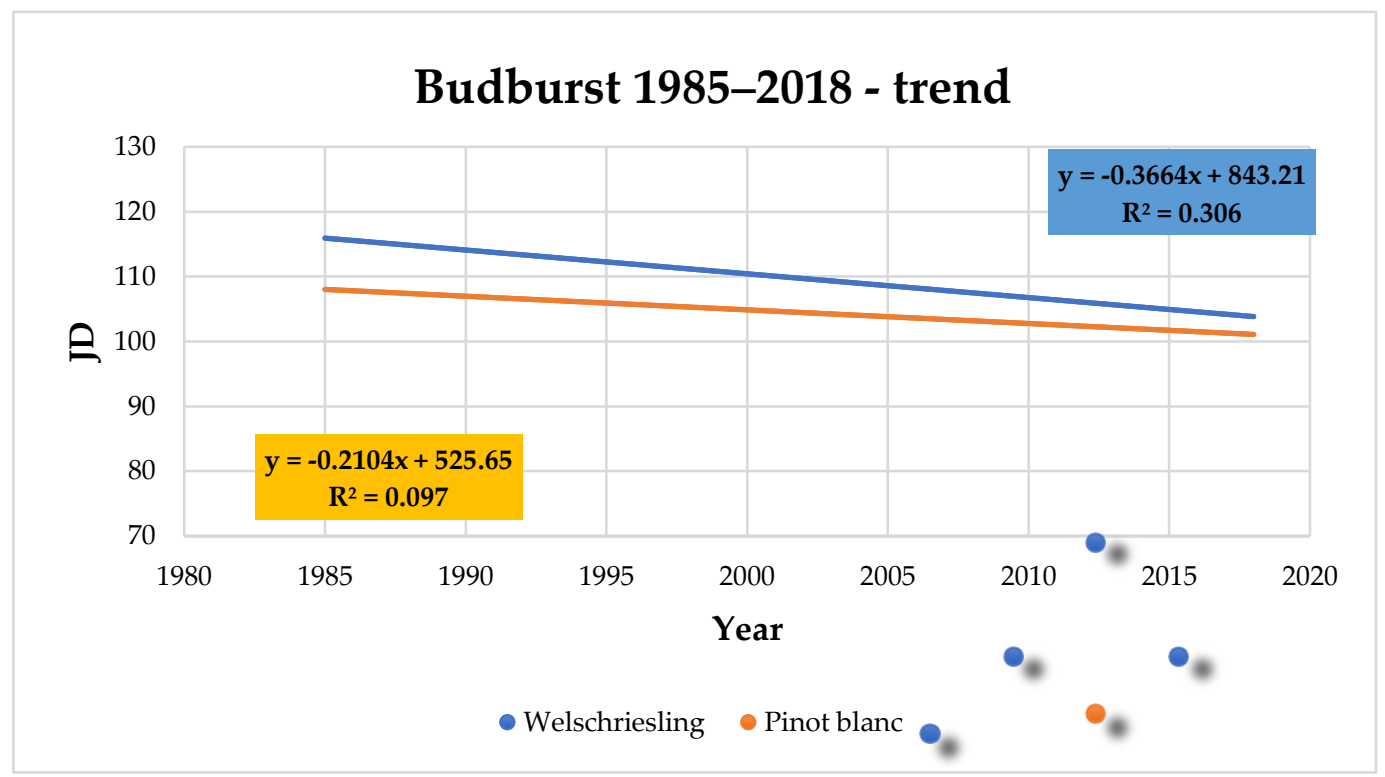

Figure 4. Beginning of budburst (JD) in Welschriesling and Pinot Blanc - trend within the observed period.

Beginning of flowering (BBCH 61) - Welschriesling variety begun to flower on June 6 (161 JD) in average. The earliest date of the beginning of flowering was May 23, 2018 and the latest June 27, 1991. The average date of the beginning of flowering in Pinot Blanc was June 4 (155 JD), with the earliest beginning of flowering on May 5, 2018 and the latest on June 20, 1991. The trend of earlier flowering date is statistically significant in both varieties (Welschriesling $r=-0.51$, Pinot Blanc $r=-0.42$ ) at $p$ level $<0,05$ (Welschriesling $\mathrm{p}=0.002$, Pinot Blanc $\mathrm{p}=0.0125)$. Comparing to 1985-1994 period beginning of flowering 
in Welschriesling was by 10 days earlier and in Pinot Blanc by 7 days on average in 20092018 period (Figure 5).

The average maximum temperature and average monthly temperature in May have the highest impact on the beginning of flowering. With the average maximum temperature the correlation coefficients were $r=-0.82$ in Welschriesling and $r=-0.89$ in Pinot Blanc which indicates moderately strong relationship between the variables. beginning of flowering and the average maximum temperature in May. Statistically significant correlation is confirmed with $p=0.0000$ in both varieties. Correlation coefficients for relation between the beginning of flowering and the average monthly temperature in May were $r=-0.72$ (Welschriesling) and $r=-0.83$ (Pinot Blanc), $p=0.0000$ for both varieties.

Moderately close relationship between the beginning of flowering and the average monthly temperature in April and the average maximum temperature in April is also statistically significant. With the average maximum temperature in April the correlation coefficients were $r=-0.64$ (Welschriesling) and $r=-0.63$ (Pinot Blanc) at $p 0.0000$ and 0.0001 respectively. With the average monthly temperature in April correlation coefficient was $r$ $=-0.56$ in both varieties $(p=0.0005$ and 0.0006 , respectively).

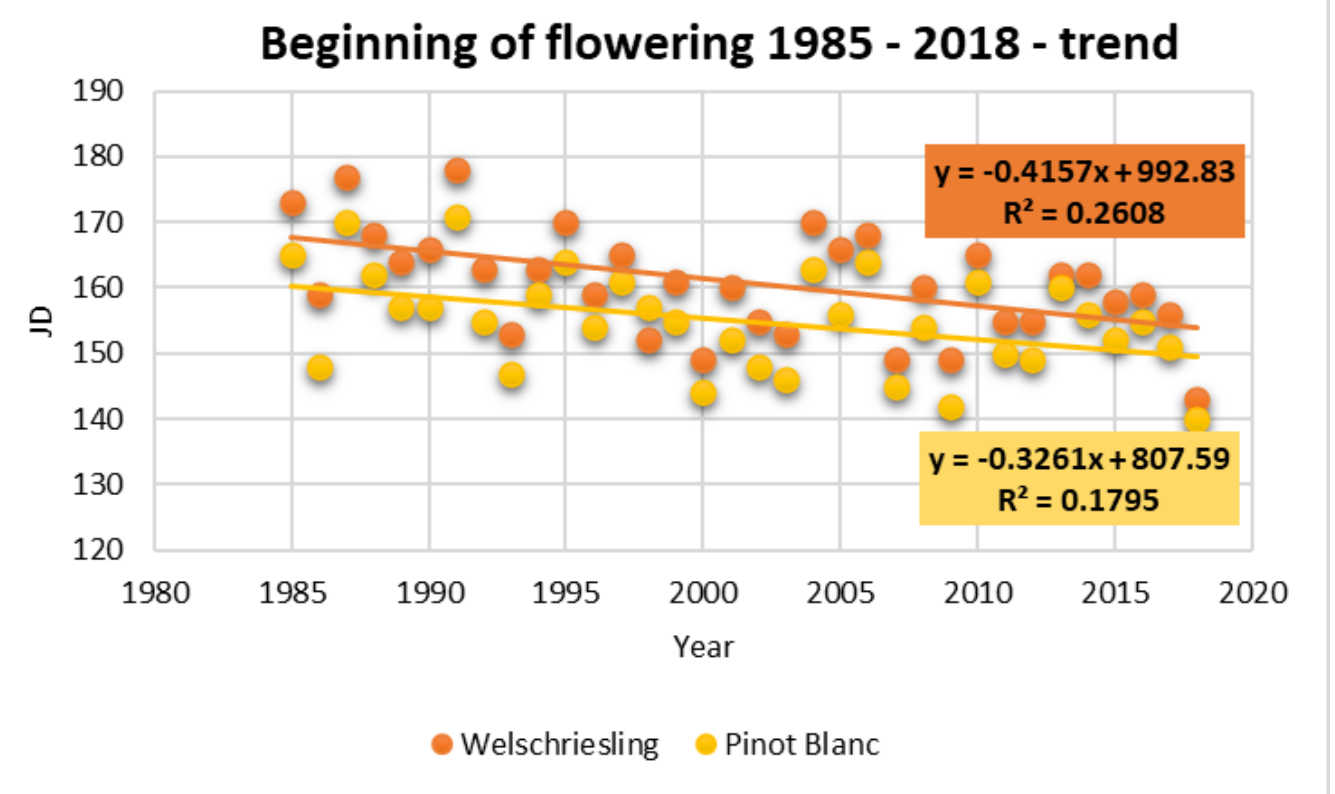

Figure 5. Beginning of flowering (JD) in Welschriesling and Pinot Blanc - trend within the observed period.

End of flowering (BBCH 69) - onset of the stage corresponds to the lenth of flowering phenophase and the trend replicates the beginning of flowering. The average length of flowering in Welschriesling was 11 days (within the range 6-15 days) while 12 days in Pinot Blanc (range 8-17 days).

Softening of berries (BBCH 85) - berries of Welschriesling begun to soften on August 19 (231 JD) in avarage. The earliest date of the beginning of berry softening was July 28, 2018 and the latest September 9, 1985. Berries of Pinot Blanc begun to soften on August 10 (222 JD) in average. The earliest date of the beginning of berry softening was July 20, 2018 
and the latest September 2, 1985. In both varieties assessed, it was the first and the last year of the evaluated period. The trend of earlier softening over the assessed period of 34 years is statistically significant with $p=0.0000$ and correlation coefficient $r=-0.7$ for both varieties. In 2009-2018 the beginning of softening was by 18 days earlier compared to 1985-1994 period in both varieties (Figure 6) .

There was found highest, statistically significant impact of the average maximum temperature in June on the beginning of ripening (veraison). Value of $\mathrm{r}=-0.79$ (Welschriesling) and $\mathrm{r}=-0.76$ (Pinot Blanc) indicates moderately close relationship, $\mathrm{p}=$ 0.0000 for both varieties. Statistically significant moderately strong correlation was confirmed between the average monthly temperature in June and the beginning of ripening, $r=-0.76$ (Welschriesling) and $r=-0.71$ (Pinot Blanc), $p=0.0000$ for both varieties.

Lower level of correlation, though still statistically significant at $p<0,05$, was found between veraison and the average maximum temperature in July $(r=-0.4$ for Welschriesling and $r=-0.36$ for Pinot Blanc, $p=0.019$ and 0.037 , respectively), between veraison and the average maximum temperature in August $(r=-0.4$ for Welschriesling and $r=-0.41$ for Pinot Blanc, $p=0.02$ and 0.016, respectively) and between veraison and the average monthly temperature in August $(r=-0.37$ for Welschriesling and $r=-0.4$ for Pinot Blanc, $\mathrm{p}=0.03$ and 0.02 , respectively).

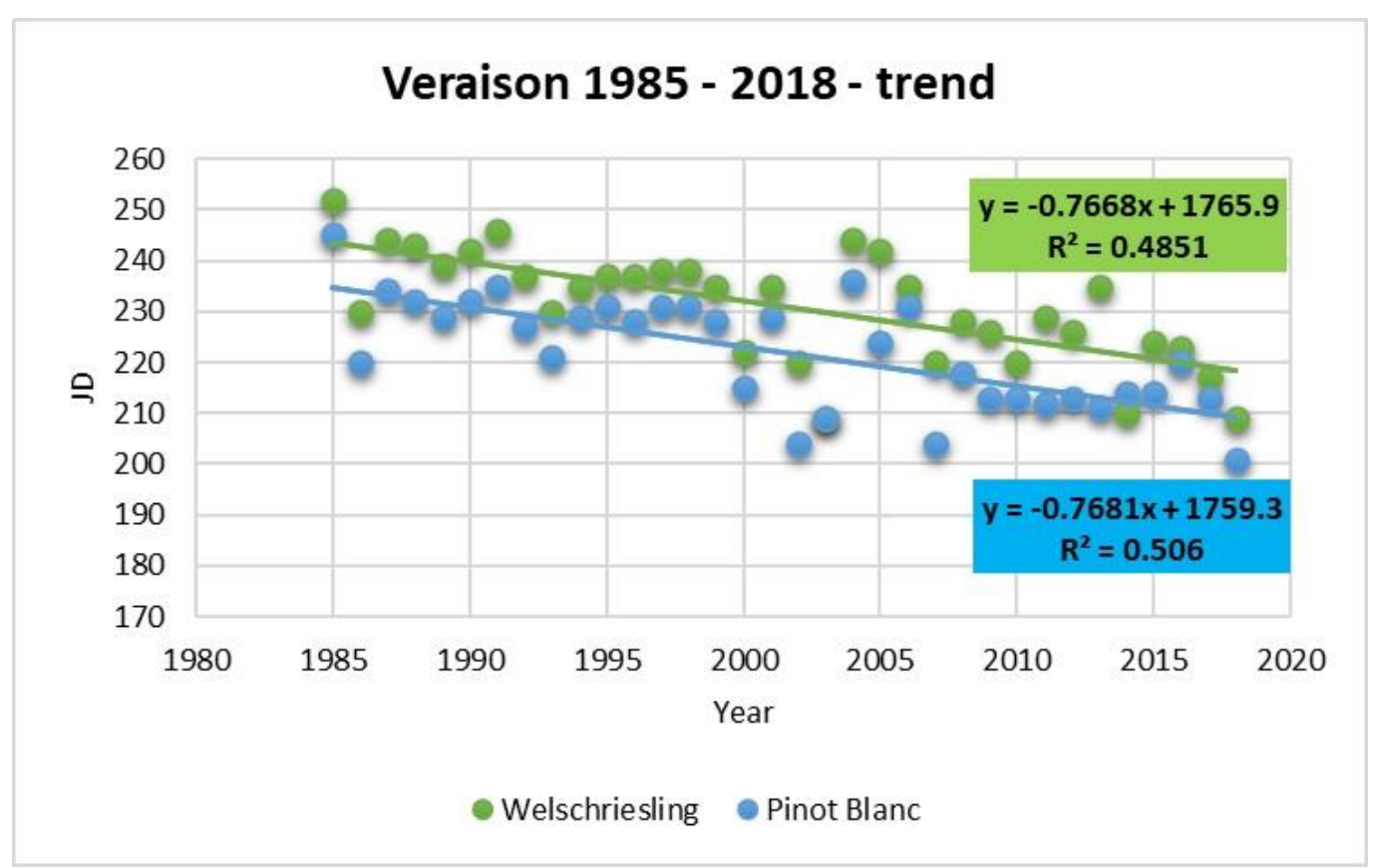

Figure 6. Beginning of berry softening (JD) in Welschriesling and Pinot Blanc - trend within the observed period.

Ripeness (harvesting) $\mathrm{BBCH} 89$ - the average harvest date of Welschriesling was October 10 (283 JD). The earliest harvest date was September 16, 2002 and the latest was October 27, 2008. Compared to 1985-1994 period the harvest date in 2009-2018 period was by 8 days earlier, the trend of earlier harvest date is not statistically significant $(r=-0.27$, $\mathrm{p}=0.12)$.

The average harvest date of Pinot Blanc was September 30 (273 JD). The earliest harvest date was September 16, 2015 and the latest was October 18, 2016. Compared to 
1985-1994 period the harvest date in 2009-2018 period was by 10 days earlier, the trend of earlier harvest date is statistically significant $(\mathrm{r}=-0.4, \mathrm{p}=0.02)$ (Figure 7).

The strongest correlation in Pinot Blanc was found between the harvest date and the average temperature in August $(r=-0.55, p=0.0008)$. In Pinot Blanc, the correlation between the harvest date and the average temerature in August had $r=-0.4$ and $p=0.02$. Both varieties show relatively balanced correlation of harvest date to the average monthly temperature and the average maximum temperature in June. Welschriesling showed statistically significant correlation between the harvest date and the average temperature in June with $r=-0.43$ and $p=0,01$. In Pinot Blanc, the values $r=-0.47$ and $p=0.005$ were obtained in correlation of the harvest date to the average monthly temperature in June while $r=-0.44$ and $p=0.009$ for the average maximum temperature in June. Statistically significant corrrelation between the harvest date and temperature in July and September was not found.

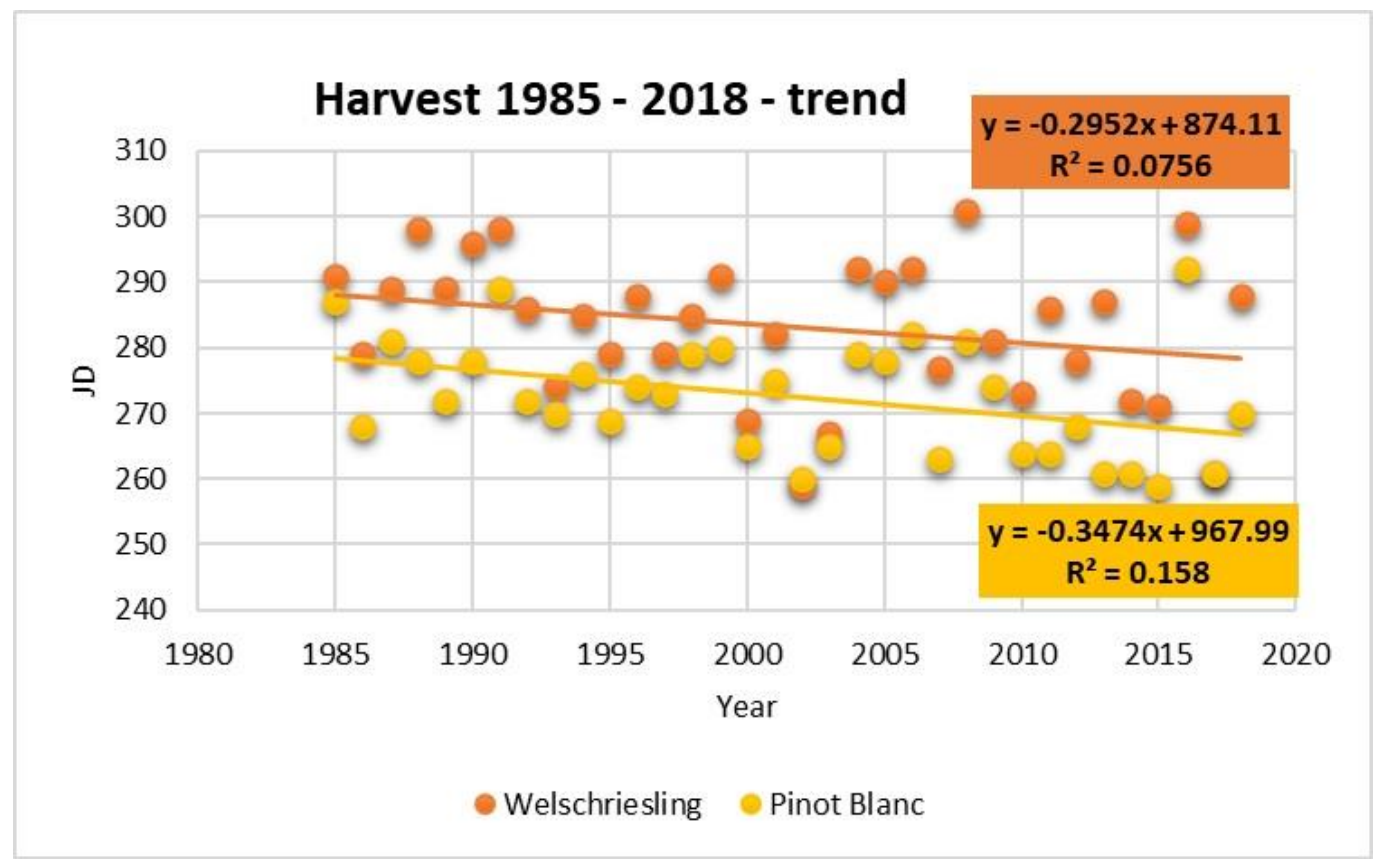

Figure 7. Harvest date (JD) in Welschriesling and Pinot Blanc - trend within the observed period.

\subsection{Interphase intervals}

Budburst - beginning of flowering (BBCH 08-BBCH 61) - the average length of the interphase interval was 51 days in Welschriesling and 50 days in Pinot Pinot Blanc. The longest interval was recorded in 1991, 71 and 70 days, respectively while the shortest in 1993, 35 and 34 days, respectively. Length of the interval budburst - beginning of flowering does not show statistically significant trend of shortening over the observed 1985-2018 period in either of the varieties.

The average GDD value for the interphase interval budburst - beginning of flowering was 281.2 (range from 226.5 to 324.5) in Welschriesling and 242.6 (range from 194.5 to 314.4) in Pinot Blanc. Only in Pinot Blanc, the trend of slightly decreasing GDD is statistically significant $(r=-0.43, p=0.012)$. 
At the average length of the interval beginning of flowering - end of flowering (BBCH 61- BBCH 69) of 11 days (Welschriesling) and 12 days (Pinot Blanc). The average GDD for the 1985-2018 period were 99,0 (range 62.0-154.2) for Welschriesling and 100.1 (range 63.3-156.3) for Pinot Blanc. Only the trend of GDD increase in Pinot Blanc is statistically significant $(\mathrm{r}=0.53, \mathrm{p}=0.0011)$.

End of flowering - berry softening (BBCH 69-BBCH 85) - the average length of the interphase interval end of flowering - berry softening over the observed 34 years period reached 59 days for Welschriesling (range 37-70 days). The trend of shortening the length of the interval is relatively slight $(r=-0.48)$ but statistically significant $(p=0,0038)$. When comparing the periods 1985-1994 and 2009 - 2018 the interval length was 8 days shorter in the later period. For Pinot Blanc, the average length of the interval was 55 days (range 40-67 days). The trend of shortening the length of the interval is moderate $(r=-0.56)$, statistically significant ( $p=0.0006$ ). When comparing the periods 1985-1994 and 20092018 the interval length was 9 days shorter in the later period. The average GDD value was 620.3 for Welschriesling (range 394.1-729.7) and 575.9 for Pinot Blanc (range 436.6711). For Pinot Blanc, there is statistically significant slight decrease in GDD value $(\mathrm{r}=-$ $0.38, \mathrm{p}=0.0284)$.

Berry softening - harvest date_(BBCH 85-BBCH 89) - the average length of the interphase interval berry softening - harvest date fot the observed 1985-2018 period was 53 days for Welschriesling (range 40-80 days) and 51 days for Pinot Blanc (range 39-71 days). In both varieties, there is statistically significant moderate trend of the interval lengthening with values $r=0.51$ and $p=0.0021$ for Welschriesling and $r=0.53$ and $p=$ 0.0013 for Pinot Blanc. The extension of the berry softening - harvest date interval was on average 9 days for Welschriesling and 7 days for Pinot Blanc in 2009-2018 compared to 1985-1994 period. For both varieties the GDD value showed statistically significant moderate trend of increase with $r=0.67$ (Welschriesling) and 0.65 (Pinot Blanc), $p=0.0000$ for both varieties. The average GDD value of the BBCH 89-BBCH 89 interval was 307.3 (range 156-617.7) for Welschriesling and 374,2 (range 193.8-679.9) for Pinot Blanc.

Length of the season budburst - harvest date (BBCH08-BBCH 89) - there was no statistically significant change in the length of the season from budburst to harvest date found in either of the varieties. The average length of the season reached 173 days in Welschriesling and 168 days in Pinot Blanc, with greater variance in Welschriesling (139 to 196 days) than in Pinot Blanc (153 to 192 days). When comparing the period 2009-2018 and the period 1985-1994 the difference in the average length of the season is - 1 day in Welschriesling and -5 days in Pinot Blanc. However, the $r$ and $p$ values do not confirm the trend of changing the length of the season from budburst to harvest date $(\mathrm{r}=0.057, \mathrm{p}=$ 0.75 for Welschriesling and $r=-0.13, p=0.46$ for Pinot Blanc).

\section{Discussion}

The results achieved show the impact of climate change on the phenology of selected grape vine (Vitis vinifera L.) varieties in conditions of Slovakia (Central Europe). We 
focused on assessing the impacts of temperature changes on grape vine (Vitis vinifera L.) phenology. Changes of other climatic factors have not been the subject of this work.

Viticulture is considered a climate-sensitive agricultural system used as an indicator of both historical and current climate changes [36]. Climate and temperature in particular play a key role in grapevine physiology and phenology. The links between grape production, wine quality, climatic conditions and geographical origin are coupled, which makes the ongoing climate change a rather difficult issue for this economic sector [37]. Given the strong sensitivity of the grapevine to atmospheric factors, climate change can pose an important challenge for this sector [38]. At the same time, suitability of grapevine varieties will be affected and historically grown combinations (and identifications) of certain varieties with certain wine-growing areas are likely to be disrupted. [39]. The suitability of vine varieties is strongly linked to regional environmental conditions and growers tend to choose the varieties that best suit these conditions. A high consistency between the current production areas and the optimal climatic zones is therefore envisaged for the variety in question. However, climate change is expected to pose new challenges for the long-term choice of varieties [40].

Phenological shifts are one of the most pronounced biological effects of global warming. [41]. In years with extreme weather conditions, phenological events started very early or very late [42]. Phenological diversity provides a mechanism to help growers adapt viticulture to climate change - by planting different varieties that will grow well in both the current and future climate [43]. Despite strong regional heterogeneity, based on climate change scenarios, significantly earlier onset of phenophases (budburst, flowering, veraison, harvesting, with consequences also at corresponding phenophase intervals is assumed $[44,38]$. In the wine-growing regions of France, they expect climate change to shift the entire phenological calendar towards earlier dates by 20-40 days and, on the other hand, new areas in northern France will become suitable for viticulture [45].

An increase in the average annual temperature was observed in various winegrowing regions of Europe. In south-west Germany, since the 1970s, average annual temperatures have increased by $2.1^{\circ} \mathrm{C}$ [6], in Slovenia there is an increase of $0.06{ }^{\circ} \mathrm{C}$ per year [46], in Mediterranean France there was an increase of $1.3^{\circ} \mathrm{C}$ [7] between 1980 and 2006. Our results confirm the trend of an increase in average annual temperature, with an increase of $1.4{ }^{\circ} \mathrm{C}$ indicating an increase in the average annual temperature of $0.04{ }^{\circ} \mathrm{C}$ per year.

Also, the average temperature of the growing season (IV. -IX.) shows significant changes. The increase is announced from different areas of Europe [23, 46, 47, 48, 49]. In Italy, the Venetian area experienced an increase in average vegetation temperature (19642009) of up to $2.3^{\circ} \mathrm{C}$ [50]. It has reached an increase of $+1.5^{\circ} \mathrm{C}$ in our geographical zone, which is significantly lower than in southern Europe.

The increase of average monthly temperatures plays an important role in the earlier onset of individual phenophases. Spring thermal conditions play a key role, especially in the flowering period, which in turn affects the following phenophases [51]. Temperatures can be very variable within the wine-growing area and are closely related to the local 
environment [52]. In the conditions of Slovakia, the most significant increase in average monthly temperatures was recorded in February, April, and November.

From the bioclimatic indices the GDD achieves significant increase, which was also observed in Hungary. Over the past 30 years, it has risen highly statistically above 1240 degrees [23]. In France (Burgundy), it also achieved a highly significant increase of 270 to 370 GDD [53]. In the north-west of Spain, they found a high degree of association (dependence) of the onset of phenophase and GDD [54]. In our conditions, the average GDD reached 1360 degrees with a significant growth trend and an extremely high value of 1646.7 degrees in 2018.

The Huglin index has proven to be a better predictor than other similar bioclimatic indices calculated for the growing season. This may be related to additional information contained in this index, such as the average length of the day in relation to latitude [55]. Using the Huglin index, possible extensions of areas suitable for viticulture as well as suitable grapevine varieties have been specified. The optimal grapevine varieties are substituted by those more suitable for a warmer climate (south-west Germany) [56]. The increase in the Huglin Index (HI) as an indicator of the suitability of growing varieties under given conditions is confirmed in different parts of Europe [57]. In south-west Germany it has increased from 1685 to 2063 [6], in Hungary in the Sopron wine region over the last 35 years the HI value has also increased above 2000 degrees [23]. These findings confirm the trend of $\mathrm{HI}$ increase that we have found in our conditions. At the same time, by moving to a warmer zone of suitability for individual varieties, higher HI confirms the possibilities of growing new, more demanding varieties, but also the achievement of higher quality grapes of currently grown varieties.

The findings so far confirm that northern wine-growing regions are more likely to be profiting from the global warming. There is anticipated earlier start of the growing season, earlier ripening of grapes and an increase in the content (quality) of grapes [58, 59, 50, 48] with forecasts of continued acceleration of the onset of phenophases in the following decades [47].

While in the northern regions of Europe, higher temperatures in the spring period cause earlier budburst by 11 to 18 days [6, 60,49], in southern Europe, Italy, Serbia [50, 48], the budburst shows great year-on-year differences, but no trend. In our terms, we found a significant slight trend of earlier budburst of Welschriesling by 7 days, but for Pinot Blanc the trend is insignificant.

An earlier flowering in the interval of -13 to -22 days is reported by several authors $[6,60,48,49]$ with the fact that, unlike the budburst phenophase, there are also demonstrated trends of earlier flowering in southern Europe (in Italy for the period 19642009 by 13 to 19 days earlier flowering [50]). In our conditions, between 1985 and 2018, we found an earlier flowering by 7 to 10 days, with the most significant impact of the average and maximum temperatures in May and April. In Portugal, maximum temperatures $\left(\mathrm{T}_{\max }\right)$ in March and April [61] are reported as significant predictors of flowering.

Advanced onset of phenophases is manifested in the beginning of berry ripening [6, $60,50,48]$ within the interval of -13 to -22 days, which corresponds to the results achieved 
by us -earlier ripening in both Welschriesling and Pinot Blanc by 18 days. In our conditions, the most significant impact on this phenophase showed the average maximum and average temperature in June, followed by the average maximum temperatures in July and August, and the average temperature in August. In Portugal, $\mathrm{T}_{\min }, \mathrm{T}_{\max }$ and $\mathrm{T}_{\text {mean }}$ in March to July period are reported as significant predictors of grapes ripening [61].

The greatest shift, but also a great variation, is indicated for the harvest of grapes (ripeness). While in Palatinate, Southwestern Germany, since the 70s of XX century they observed a harvest 25 to 40 days earlier [6], in Italy in 1964-2009 a trend of 13 to 19 days earlier harvest [49], in Mediterranean France an earlier harvest by three weeks [7]. Earlier harvest dates are also observed in Australia [62, 63]. Our results do not match with previous data, because grape harvesting is more technological (wine-growing) than phenological term. In the case of suitable temperature conditions, grapes are harvested later, with higher quality, which is, as mentioned above, the actual positive effect of warming (climate change) for the northern wine regions. Therefore, the Welschriesling variety does not show a significant trend of an earlier harvest date. Only the Pinot Blanc variety shows a significant slight trend (-10 days).

As to interphase intervals, results from different areas of Europe vary. While in Germany (Lower Franconia) there was observed the trend of phenological intervals shortening [59], in Serbia, in the region of Sremski Karlovci, it is reported that the observed warming and change in the onset of phenophases did not significantly affect the duration of growth intervals [48]. In our conditions, we found a relatively mild, statistically significant trend of shortening the interphase end-of-flowering - berry softening (maturation) by 8 to 9 days. On the other hand, for both varieties, there is statistically moderately strong trend of lengthening the interval berry softening - harvest by 7 to 9 days.

The length of the season from budburst to harvest shows great variation, but there is no significant change. For the period of 1985-2018, Welschriesling shows an average reduction by 1 day while Pinot Blanc by 5 days. In Slovenia, they report a reduction of 15 to 27 days in different varieties [46].

\section{Material and methods}

\subsection{Locality, experimental base}

Long-term data obtained at the locality of the Cultivar Testing Station in Dolné Plachtince (N48 ${ }^{\circ} 12.327^{\prime}$ E19 $\left.19.064^{\prime}\right)$ which belongs to the Central Slovakian wine region, district of Modrý Kameň, were used for evaluation of climate change impact on grapevine phenology. The Station is specialised in the testing of fruit crop and grapevine cultivars. The site is located in the southern part of the Krupinská planina, exposed to south-west with $5-10{ }^{\circ}$ inclination, at the altitude of $228 \mathrm{~m}$ a.s.l. Soil is loam clay illimerisated brown soil, $\mathrm{pH}$ 6.2. Mean annual temperature (1960-1990 reference period) is $9.1{ }^{\circ} \mathrm{C}$, average temperature of growing season is $16.0^{\circ} \mathrm{C}$, annual precipitation $648 \mathrm{~mm}$, growing season precipitation $362 \mathrm{~mm}$, average annual sunshine duration is 1983 hours, average sunshine duration within growing season equals 1500 hours. The data were obtained from the 
experimental vineyard with cultivar collection planted in $3.0 \times 1.2 \mathrm{~m}$ spacing, trained in the Rhein-Hessen form.

4.2 Evaluated varieties Vitis vinifera $\mathrm{L}$.

For the evaluation of climate change impact on grapevine phenology Welschriesling and Pinot Blanc were chosen as model grapevine varieties.Welschriesling is the second most spread variety in Slovakia, with late ripening term and Pinot Blanc is also among widely grown varieties in Slovakia, with medium late ripening.

4.3 Temperature data and indices

Temperature data of the period 1985-2018 were obtained from the Meteorological station in Dolné Plachtince. For the evaluation there were used - the average annual temperature, the growing season (April - September) average temperature, the monthly average temperatures, the average maximum temperature in month (April - September).

Table 1 Long-term normal (1960-1990) of average temperatures $\left({ }^{\circ} \mathrm{C}\right)$ at the locality of Dolné Plachtince

\begin{tabular}{|c|c|c|c|c|c|c|c|c|c|c|c|c|c|}
\hline Month & I. & II. & III. & IV. & V. & VI. & VII. & VIII. & IX. & X. & XI. & XII. & Year \\
\hline $\begin{array}{c}\text { Average air } \\
\text { temperature }\end{array}$ & & & & & & & & & & & & & \\
$\left({ }^{\circ} \mathrm{C}\right)$ & -3.2 & -1.1 & 4.2 & 9.7 & 15.1 & 18.1 & 20.1 & 19.1 & 14.8 & 9.2 & 3.6 & -0.7 & $\mathbf{9 . 1}$ \\
\hline
\end{tabular}

4.4 Termal indices

GDD (Growing degree days) - sum of effective temperatures (effective temperature $=$ the average daily temperature -10$)$. Temperature of $10 \circ \mathrm{C}$ is vegetation zero $\left(\mathrm{T}_{\text {base }}\right)$ for grapevine (Vitis vinifera L.). For calculation of GDD for the locality a period from April 1 to September 30 is considered, for the variety a period from budburst to harvest date.

In the work, modified GDD for principal growing season (PGS) which reflects an interannual temperature variability and better expresses impact of climate change (warming) on earlier beginning and ending of the growing season.

PGS (principal growing season) - beginning of the PGS is the first day of 6 day period with discontinued average daily temperature higher than $10^{\circ} \mathrm{C}$, end of the PGS is the last day prior to 6 day period with discontinued average daily temperature lower than $10{ }^{\circ} \mathrm{C}$.

$\mathrm{HI}$ - Huglin index is calculated with use of following formula:

$$
\sum_{\text {April } 1}^{\text {Sept } 30} \frac{[(\text { Tmean }-10)+(\operatorname{Tmax}-10)]}{2} \cdot K
$$

$T_{\text {mean }}=$ daily mean temperature

$T_{\max }=$ daily maximum temperature

baseline temperature $=10^{\circ} \mathrm{C}$

$K=$ parameter dependent on the latitude of the location; the sum is multiplied by a factor $K$ depending on the latitude of the location, taking into account the length of the day in northern latitudes ( $\mathrm{K}$ for the locality of Dolné Plachtince is 1,06) [64, 65] 
Trends of temperature and thermal indices were evaluated with use of simple linear regression for 1985-2018 period.

\subsection{Evaluated phenological phases and interphase intervals}

The BBCH scale [66] was used to set onset of the following phenophases in grapevine (Vitis vinifera L.):

Budburst (BBCH 08) - sprouting, green shoot tips clearly visible

Beginning of flowering (BBCH 61$)-10 \%$ of flowerhoods fallen

End of flowering (BBCH 69) - more than $80 \%$ of flowerhoods fallen

Beginning of ripening (BBCH 85) - softening of beries

Harvest date (harvest) (BBCH 89) - berries ripe for harvest

Date of phenophase onset was transformed to Julian Day value (JD). The trends of the phenophases onset for 1985-2018 period were assessed, the phenophase onset date and the average monthly temperatures or GDD values were correlated.

Besides the phenophase onset, the length of following interphase intervals (days) and the trend of interphase interval length for 1985-2018 period were evaluated.

Budburst - beginning of flowering (BBCH 08-BBCH 61)

Beginning of flowering - end of flowering (BBCH 61-BBCH 69)

End of flowering - softening of berries (BBCH 69-BBCH 85)

Softening of berries - harvest date (BBCH 85-BBCH 89)

Within each interphase interval there was calculated the average temperature of the interphase interval period $\left({ }^{\circ} \mathrm{C}\right), \Sigma \mathrm{GDD}$ of the interphase interval period and in the interphase intervals budburst - beginning of flowering, softening of berries - harvest date also number of days with active temperature $>10^{\circ} \mathrm{C}$.

4.6 Method of the obtained data evaluation

Calculation of the average values of the parameters, range - minimum and maximum values, processing linear trends of temperature, bioclimatic indices and phenological phases and linear correlations of temperatures, bioclimatic indices and phenophase onset as well as length of interphase intervals.

\subsection{Statistical processing of data}

The software Statgraphics Centurion Version 18. 1. 13 was used for data processing simple regression, coefficients of correlation, significance of trends and correlations at $95 \%$ level, $\mathrm{p}<0,05$ (ANOVA). Graphs were prepared with MS Excel software.

\section{Conclusions}

Climate change caused temperature changes in wine regions all over the world. Knowing the reaction of grapewine on these changes is important for timely adaptation of the viticultural and wine-producing sector, a proper option of varieties, and adaptation of growing technologies to changed conditions. Influence of warming on grapevine (Vitis vinifera L.) phenology was evaluated in con-ditions of Central Europe, Slovakia, Slovakian 
wine region. Based on 34 years period (1985-2018) climatic and phenological data influence of temperature changes on the onset of phenophases and length of interphase intervals in Welchriesling and Pinot Blanc varieties. Increase in the average year temperature $+1.4{ }^{\circ} \mathrm{C}$, and the average sea-son temperature $+1.5^{\circ} \mathrm{C}$ was found. The average value of $\mathrm{HI}$ at the Locality of Dolné Plachtince in 2009-2018 period was $2189{ }^{\circ} \mathrm{C}$ which is lower than in 1961-1990 (refer-ence period) $1790{ }^{\circ} \mathrm{C}$ which indicates increase of HI value $122{ }^{\circ} \mathrm{C}$ every ten years. The HI value of $1790{ }^{\circ} \mathrm{C}$ corresponds to cool wine region (interval 1500 - 1800) while 2189 classifies the region to moderately warm wine region category suitable also for very late varieties. In the evaluated phenophases there was found advancement - the earli-er budburst by 5-7 days, the earlier beginning of flowering by 710 days, and the earlier berry softening by 18 days. The obtained results confirm the fact that climate warming in Central Europe (and in Slovakia) and northern wine regions has not caused changes in the grapevine phenology yet which could call forth serious adaptation measures. Earlier veraison opens the space for increased grape quality, however.

Supplementary Materials: The following are available online at www.mdpi.com/xxx/s1, Table S1: Bioclimatic indices, Table S2: Monthly, year, and season temperature averages, Table S3 Monthly average maximum temperature, Table S4: Pinot Blanc phenophases, Table S5: Welschriesling phenophases.

Author Contributions: Conceptualization, S.B, B.Š.; methodology, S.B., F.T.; software, S.B.; validation, S.B., O.P.; formal analysis, S.B., B.Š.; investigation, S.B., B.Š., O.P., Z.K., F.T.; resources, S.B., B.Š., F.T.; data curation, S.B., B.Š., O.P.; writing-original draft preparation, S.B., O.P.; writingreview and editing, S.B., O.P.; visualization, S.B., Z.K.; supervision, S.B, O.P.; project administration, B.Š.; funding acquisition, B.Š. All authors have read and agreed to the published version of the manuscript.

Funding: This research is funded by The Slovak Ministry of Education, Science, Research and Sport, project "Response of Ecosystem Services of Grape Growing Country to Climate Change Regional Impact- Change of Functions to Adaptation Potential“, grant number VEGA 1/0767/17

Conflicts of Interest: The authors declare no conflict of interest.

\section{References}

1. Jones, G.V. Climate, grapes and wine: structure and suitability in a changing climate. Acta Hortic. 2012, 932, 19-28.

2. Duchene, E.; Schneider, C. Grapevine and climatic changes: a glance at the situation in Alsace. Agron. Sust. Dev. 2005, 25, 9399.

3. Jones, G.V.; White, M.A.; Cooper, O.R.; Storchmann, K. Climate change and global wine quality. Clim. Change 2005, 73, 319343, doi:10.1007/s10584-005-4704-2.

4. Fraga, H.; Malheiro, A.C.; Moutinho-Pereira, J.; Santos, J.A. An overview of climate change impacts on European viticolture. Food Energy Secur. 2012, 1 (2), 94-110.

5. Gentilucci, M.; Materazzi, M.; Pambianchi, G.; Burt, P.; Guerriero, G. Temperature variations in Central Italy (Marche region) and effects on wine grape production. Theor. Appl. Climatol. 2020, 140, 303-312.

6. Koch, B.; Oehl, F. Climate Change Favors Grapevine Production in Temperate Zones. Agric. Sci. 2018, 9, $247-263$.

7. Laget, F.; Tondut, J.-L.; Deloire, A.; Kelly, M.T. Climate trends in a specific mediterranean viticultural area between 1950 and 2006. J. Int. Sci. Vigne Vin. 2008, 42, 113-123.

8. Labudová L.; Faško P.; Ivaňáková G. Changes in climate and changing climate regions. Moravian Geographical Reports. 2015, $23(3), 71-82$. 
9. Hlaszny, E.; Hajdu, E.; Bisztray, G.; Ladányi, M. Comparison of budburst models predictions for Kékfrankos. Appl. Ecol. Env. Res. 2012, 10(1), 75-86.

10. Anderson, K.; Findlay, Ch.; Fuentes, S.; Tyerman, S. Viticulture, wine and climate change. Garnaut Climate Change Review 2008, 22 p.

11. Keller, M. Managing grapevines to optimise fruit development in a challenging environment: a climate change primer for viticulturists. Aust. J. Grape Wine Res. 2010, 16, 56-69.

12. Malheiro, A.C.; Santos, J.A.; Fraga, H.; Pinto, J.G. Climate change scenarios applied to viticultural zoning in Europe. Clim. Res. 2010, 43, 163-177, doi:10.3354/cr00918.

13. Malheiro, A.C.; Santos, J.A.; Pinto, J.G.; Jones, G.V. European viticulture geography in a changing climate. Bulletin de l'OIV 2012, 85, (971-972-973), 15-22.

14. Fraga, H.; Malheiro, A.C.; Moutinho-Pereira, J.; Santos, J.A. Future scenarios for viticultural zoning in Europe: ensemble projections and uncertainties. Int. J. Biometeorol. 2013, 57, 909-925.

15. Webb, L.B.; Watterson, I.; Bhend, J.; Whetton, P.H.; Barlow, E.W.R. Global climate analogues for winegrowing regions in future periods: projections of temperature and precipitation. Aust. J. Grape Wine Res. 2013, 19, 331-341.

16. Bonfante, A.; Monaco, E.; Langella, G.; Mercogliano, P.; Bucchignani, E.; Manna, P.; Terribile, F. A dynamic viticultural zoning to explore the resilience of terroir concept under climate change. Sci. Total Environ. 2018, 624, 294-308.

17. Cradock-Henry, N.A.; Blackett, P.; Hall, M.; Johnstone, P.; Teixeira, E.; Wreford, A. Climate adaptation pathways for agriculture: Insights from a participatory Process. Environ. Sci. Policy 2020, 107, 66-79.

18. De Orduńa R.M. Climate change associated effects on grape and wine quality and production. Food Res. Int. 2010, 43, 18441855.

19. Biasi, R.; Brunori, E.; Ferrara, C.; Salvati, L. Assessing Impacts of Climate Change on Phenology and Quality Traits of Vitis vinifera L.: The Contribution of Local Knowledge. Plants 2019, 8, 121, doi:10.3390/plants8050121.

20. Blank, M.; Hofmann, M.; Stoll, M. Seasonal differences in Vitis vinifera L. cv. Pinot noir fruit and wine quality in relation to climate. OENO One 2019, 2, 189-203.

21. De Rességuier, L.; Mary, S.; Le Roux, R.; Petitjean, T.; Quénol, H.; van Leeuwen, C. Temperature Variability at Local Scale in the Bordeaux Area. Relations With Environmental Factors and Impact on Vine Phenology. Front. Plant Sci. 2020, 11, 515, doi:10.3389/fpls.2020.00515.

22. Cameron, W.; Petrie, P.R.; Barlow, E.W.R.; Patrick, C.J.; Howell, K.; Fuentes, S. Advancement of grape maturity: comparison between contrasting cultivars and regions. Aust. J. Grape Wine Res. 2020 26, 53-67.

23. Kovacs, E.; Puskas, J.; Pozsgai, A. Positive Effects of Climate Change on the Field of Sopron Wine-Growing Region in Hungary. T.S. Karacostas et al. (eds.), Perspectives on Atmospheric Sciences, Springer, Atmospheric Sciences, 2017, doi:10.1007/978-3-31935095-0_86.

24. Tissot, C.; Rouan, M.; Neethling, E.; Quenol, H; Brosset, D. Modeling of vine agronomic practices in the context of climate change. BIO Web of Conferences 3, 01015, 2014, doi:10.1051/bioconf/20140301015.

25. Cola, G.; Failla, O.; Maghradze, D.; Megrelidze, L.; Mariani, L. Grapevine phenology and climate change in Georgia. Int. J. Biometeorol. 2017, 61,761-773.

26. Stewart, A.L.; Ahmed, S. Effects of climate change on fruit nutrition. Chapter 7, Srivastava, A.K., Hu, Ch. (eds. ), Fruit Crops. Elsevier, 2020, 77 - 93.

27. Mihailescu, E.; Bruno Soares, M. The Influence of Climate on Agricultural Decisions for Three European Crops: A Systematic Review. Front. Sustain. Food Syst. 2020, 4, 64, doi:10.3389/fsufs.2020.00064.

28. Tóth, J.P.; Végvári, Z. Future of winegrape growing regions in Europe. Aust. J. Grape Wine Res. 2016, 22, 64-72. 
29. Van Leeuwen, C.; Destrac-Irvine, A.; Dubernet, M.; Duchêne, E.; Gowdy, M.; Marguerit, E.; Pieri, P.; Parker, A.; de Rességuier, L.; Ollat, N. An Update on the Impact of Climate Change in Viticulture and Potential Adaptations. Agronomy 2019, 9, 514, doi:10.3390/agronomy9090514.

30. Santos, J.A. A Review of the Potential Climate Change Impacts and Adaptation Options for European Viticulture. Appl. Sci. 2020, 10, 3092; doi:10.3390/app10093092.

31. Ferretti, C.G. A new geographical classification for vineyards tested in the South Tyrol wine region, northern Italy, on Pinot Noir and Sauvignon Blanc wines. Ecol. Indic. 2020, 108, 10573.

32. Morales-Castilla, I.; de Cortázar-Atauri, I.G.; Cook, B.I.; Lacombe, T.; Parker, A.; van Leeuwen, C.; Nicholas, K.A.; Wolkovich, E.M. Diversity buffers winegrowing regions from climate change losses. Proc. Natl. Acad. Sci. USA 2020, 117 (6), $2864-2869$.

33. Cabré, F.; Nuñez, M. Impacts of climate change on viticulture in Argentina. Reg. Environ. Change 2020, $20,12$.

34. Irimia, L.M.; Patriche, C.V.; Rosca, B. Climate change impact on climate suitability for wine production in Romania. Theor. Appl. Climatol. 2018, 133,1-14, doi:10.1007/s00704-017-2156-z.

35. Karvonen, J. Changes in the grapevine's growth cycle in Southern Finland in the 2000s - comparison between two first decades. Clim. Change, 2020, 6(21), 94-99.

36. Mosedale, J.R; Abernethy, K.E.; Smart, R.E.; Wilson, R.J.; Maclean, I.M.D. Climate change impacts and adaptive strategies: lessons from the grapevine. Glob. Change Biol. 2016, 22, 3814-3828.

37. Ollat, N.; van Leeuwen, C.; de Cortazar-Atauri, I. G.; Touzard, J.-M. The challenging issue of climate change for sustainable grape and wine production. One - Climwine, 2017, 51, 2, 59-60.

38. Fraga, H.; de Cortázar Atauri, I.G.; Malheiro, A.C.; Santos, J.A. Modelling climate change impacts on viticultural yield, phenology and stress conditions in Europe. Glob. Change Biol. 2016, 22, 3774-3788.

39. Schultz, H.R; Jones, G.V. Climate induced historic and future changes in viticulture. Journal of Wine Research 2010, 21, 137-145, doi:10.1080/09571264.2010.530098.

40. Fraga, H.; Santos, J.A.; Malheiro, A.C.; Oliveira, A.A.; Moutinho-Pereira, J.; Jones, G.V. Climatic suitability of Portuguese grapevine varieties and climate change adaptation. Int. J. Climatol. 2016, 36, 1-12.

41. Sadras, V.O.; Moran, M.A. Nonlinear effects of elevated temperature on grapevine phenology. Agric. For. Meteorol. 2013, 173 $107-115$.

42. Chevet, J.-M.; Lecocq, S.; Visser, M. 2011 Climate, Grapevine Phenology, Wine Production, and Prices: Pauillac (1800-2009). Am. Econ. Rev. 2011, 101, 3, 142-46.

43. Wolkovich, E.M.; Burge, D.O.; Walker, M.A.; Nicholas, K.A. Mini-review: Ecological solutions to global food security Phenological diversity provides opportunities for climate change adaptation in winegrapes. J. Ecol. 2017, 105, 905-912.

44. Ramos, M.C.; Jones, G.V.; Yuste J. Phenology of Tempranillo and Cabernet-Sauvignon varieties cultivated in the Ribera del Duero DO: observed variability and predictions under climate change scenarios. OENO One 2018, 52, 1, 31-44.

45. Pieri, P.; Lebon, E.; Brisson, N. Climate change impact on French vineyards as predicted by models. Acta Hortic. 2012, 931, 2938.

46. Vršič, S.; Vodovnik, T. Reactions of grape varieties to climate changes in North East Slovenia. Plant Soil Environ. 2012, 58, (1), 34-41.

47. Fraga, H.; de Cortazar Atauri, I.G.; Malheiro, A.C.; Moutinho-Pereira, J.; Santos, J.A. Viticulture in Portugal: A review of recent trends and climate change projections. OENO One 2017, 51, 2, 61-69.

48. Ruml, M.; Korać, N.; Vujadinović, M.; Vuković, A.; Ivanišević, D. Response of grapevine phenology to recent temperature change and variability in the wine-producing area of Sremski Karlovci, Serbia. The Journal of Agricultural Science 2015, 154 (2), 186-206, doi:10.1017/S0021859615000453. 
49. Urhausen, S.; Brienen, S.; Kapala, A.; Simmer, C. Climatic conditions and their impact on viticulture in the Upper Moselle region. Clim. Change 2011, 109(3-4), 349-373, doi:10.1007/s10584-011-0059-z.

50. Tomasi, D.; Jones G.V.; Giust, M.; Lovat, L.; Gaiotti, F. Grapevine phenology and climate change: relationships and trends in the Veneto region of Italy for 1964-2009. Am. J. Enol. Vitic. 2011, 62(3), 329-339.

51. Malheiro, A.C.; Campos, R.; Fraga, H.; Eiras-Dias, J.; Silvestre, J.; Santos, J.A. Winegrape phenology and temperature relationships in the Lisbon vine region, Portugal. J. Int. Sci. Vigne Vin. 2013, 47, n 4, 287-299.

52. Le Roux, R.; de Resseguier, L.; Corpetti, T.; Jégou, N.; Madelin, M.; van Leeuwen, C.; Quénol, H. Comparison of two fine scale spatial models for mapping temperatures inside winegrowing areas. Agric. For. Meteorol. 2017, 247, $159-169$.

53. Xu, Y.; Castel, T.; Richard, Y.; Cuccia, C.; Bois, B. Burgundy regional climate change and its potential impac on grapevines. Clim. Dyn. 2012, 39, 1613-1626, doi:10.1007/s00382-011-1284-x.

54. Fernández-González; M., Rodríguez-Rajo, F.J.; Escuredo, O.; Aira, M.J. Influence of thermal requirement in the aerobiological and phenological behavior of two grapevine varieties. Aerobiologia 2013, 29, 523-535.

55. Gaál, M.; Moriondo, M.; Bindi, M. Modelling the impact of climat change on the Hungarian wine regions using Random Forest. Appl. Ecol. Env. Res. 2012, 10(2), 121-140.

56. Neumann, P.; Matzarakis, A. Viticulture in southwest Germany under climate change conditions. Clim. Res. 2011, 47(3), 161169, doi:10.3354/cr01000.

57. Santos, J.A.; Malheiro, A.C.; Pinto, J.G.; Jones, G.V. Macroclimate and viticultural zoning in Europe: observed trends and atmospheric forcing. Clim. Res. 2012, 51, 89-103.

58. Kartschall, T. Changes in phenology and frost risks of Vitis vinifera (cv Riesling), Meteorol. Z. 2015, 24, 2, 189-200.

59. Bock, A.; Sparks, T.; Estrella, N.; Menzel, A. Changes in the phenology and composition of wine from Franconia, Germany, Clim. Res. 2011, 50, 69-81.

60. Kast, W. K.; Rupp, D. Effects of climatic change on phenology and ripening conditions of grapevine, Mitt. Klosterneuburg, Rebe und Wein, Obstbau und Früchteverwertung 2009, 59, 1, 3-7.

61. Fraga, H.; Santos, J.A.; Moutinho-Pereira, J.; Carlos, C.; Silvestre, J.; Eiras-Dias, J.; Mota, T.; Malheiro, A. C. Statistical modelling of grapevine phenology in Portuguese wine regions: observed trends and climate change projections. J. Agr. Sci. 2016, 154, (5), 795-811, doi:10.1017/S0021859615000933.

62. Hall, A.; Mathews, A.J.; Holzapfel, B.P. Potential effect of atmospheric warming on grapevine phenology and post-harvest heat accumulation across a range of climates. Int. J. Biometeorol. 2016, 60, 1405-1422.

63. Webb, L.B.; Whetton, P.H.; Barlow, E.W.R. Observed trends in winegrape maturity in Australia. Glob. Change Biol. 2011, 17, 2707-2719.

64. Huglin, P. Nouveau mode d'évaluation des possibilities héliothermiques d'un milieu viticole. In Proceedings of the Symposium Int. sur l'ecologie de la Vigne, Constanta, Romania, 25-29 September 1978; Ministère de l'Agriculture et de l'Industrie Alimentaire: Constanta, Romania 1978; pp. 89-98.

65. Tonietto, J.; Carbonneau, A.A. Multicriteria climatic classification system for grape growing regions worldwide. Agric. For. Meteorol. 2004, 124, 81-97, doi:10.1016/j.agrformet.2003.06.001.

66. Lorenz, D.H.; Eichhorn, K.W.; Bleiholder, H.; Klose, R.; Meier, U.; Weber, E. Growth Stages of the Grapevine: Phenological growth stages of the grapevine (Vitis vinifera L. ssp. vinifera) Codes and descriptions according to the extended BBCH scale. Aust. J. Grape Wine Res. 1995, 1, 100-103. 